\title{
An Intraindividual Process Approach to the Relationship Between Extraversion and Positive Affect: Is Acting Extraverted as "Good" as Being Extraverted?
}

\author{
William Fleeson, Adriane B. Malanos, and Noelle M. Achille \\ Wake Forest University
}

\begin{abstract}
This article investigates whether rapid variation within a person in extraversion is associated with positive affect variation in that person. In Study 1, participants reported their extraversion and positive affect every $3 \mathrm{hr}$ for 2 weeks. Each participant was happier when acting extraverted than when acting introverted. Study 2 's diary methodology replicated the relationship for weekly variations in positive affect. Study 3's experimental methodology replicated the relationship when extraversion was manipulated within a fixed situation. Thus, the relationship between extraversion and positive affect, previously demonstrated between persons, also characterizes the internal, ongoing psychological functioning of individuals and is likely to be explained by something capable of rapid intraindividual variation. Furthermore, traits and states are at least somewhat isomorphic, and acting extraverted may increase well-being.
\end{abstract}

The purpose of this article is twofold. The first purpose is to investigate whether the relationship between extraversion and positive affect is evident within person over time; that is, whether short-term, fast-moving, and everyday variations in extraversion in one person are associated with fast-moving variations in that same person's positive affect. This purpose is important for at least three reasons. First, it determines whether the extraversion-positive affect relationship observed in between-persons studies is limited to a description of co-occurrences of differences between individuals or can be included in the characterization of the ongoing, internal psychological functioning of individuals. Second, it provides a test of the density distributions model of traits-specifically, that a large part of the individual differences in traits is the frequency with which individuals enact corresponding states (e.g., the frequency of acting extraverted) and that within-person variation in states is meaningful and at least somewhat isomorphic to variation in traits (Fleeson, 2001). Third, it tests the potential implication of the between-persons correlation that individuals can become happier by acting more extraverted. That is, if this is a potential route to self-improvement, it must be the case that changes within a person in extraversion are associated with changes in that person in positive affect.

The second purpose of this article is to identify the proportion of individuals who show the relationship as well as which individuals show the relationship - that is, whose variations in positive affect are predictable from their variations in extraversion. This second purpose is important for at least three reasons. First, the relation-

William Fleeson, Adriane B. Malanos, and Noelle M. Achille, Department of Psychology, Wake Forest University.

Portions of this work were presented at the 107th Annual Convention of the American Psychological Association, August 1999, Boston, Massachusetts. We thank Bob Beck and John Seta for their comments.

Correspondence concerning this article should be addressed to William Fleeson, Department of Psychology, Wake Forest University, WinstonSalem, North Carolina 27109. E-mail: fleesoww@wfu.edu ship between extraversion and positive affect increases in importance if it is a principle generally characteristic of psychological functioning rather than being limited to only those individuals who are dispositionally predisposed to benefit from it. Second, it provides another domain in which to test whether the content of behavior or its authenticity (concordance with dispositions) is more important (Emmons, Diener, \& Larsen, 1986; McGregor \& Little, 1998; Moskowitz \& Côté, 1995; Roberts \& Donahue, 1994; Ryan \& Deci, 2001; Sheldon, Ryan, Rawsthorne, \& Ilardi, 1997). Third, the larger is the proportion of individuals who show the relationship, the more widely the relationship can potentially be applied as an intervention in the service of positive psychology (Ryan \& Deci, 2001; Seligman \& Csikszentmihalyi, 2000; Sheldon \& King, 2001).

\section{The Relationship Between Extraversion and Positive Affect}

The between-persons extraversion-positive affect relationship means that more extraverted individuals are happier than are more introverted individuals, on average. Researchers have demonstrated this relationship by obtaining reports of overall or dispositional extraversion as well as of overall positive affect. Resulting correlations typically vary in the .10 to .70 range (Diener \& Lucas, 1999; Lucas \& Fujita, 2000). This finding has been reasonably robust and has been observed with self-reports on a variety of extraversion measures, in spouse reports, after social desirability was partialed out, in adults of various ages, and in at least 39 different countries (Lucas, Diener, Grob, Suh, \& Shao, 2000).

The extraversion-positive affect relationship has also been one of the more important recent findings in personality psychology, for at least two reasons. First, it adds validity and meaning to the extraversion trait, encouraging its acceptance as one of the viable ways to study personality. Second, it demonstrates that personality may be as important to psychological well-being as is circumstance. Thus, individuals may have the potential to contribute directly to their own well-being. In more general terms, the finding 
is also important to the growing interest in positive psychologythe study not only of how to ameliorate detrimental aspects of life but also of how to enhance beneficial aspects of life (Ryan \& Deci, 2001; Seligman \& Csikszentmihalyi, 2000; Sheldon \& King, 2001). In particular, this finding suggests that one potential way to increase positive affect in life is to become more extraverted.

It is not known why extraverts are happier than introverts, and at least three classes of explanations have been offered. Explanations focusing on the apparently social nature of extraversion have found little support (Emmons \& Diener, 1986; McCrae \& Costa, 1987). For example, Pavot, Diener, and Fujita (1990) showed that introverts in fact spend just about as much time with others as do extraverts and experience just about as much increase in happiness as do extraverts when spending time with others. More recently, Lucas et al. (2000) showed that socializing correlated less strongly with the core of extraversion than did positive affect and that this finding held up across 39 cultures. A second class of explanations - temperamental - proposes that individuals have baseline or set-point levels of positive affect. These dynamic equilibrium (Headey \& Wearing, 1989), set-point (Lykken \& Tellegen, 1996), and affective level (Gross, Sutton, \& Ketelaar, 1998) hypotheses suggest that happiness levels are more or less fixed within individuals at different levels because of structural differences, that homeostatic-like principles bring individuals quickly back down to their set points after positive disturbances and quickly back up to their set points after negative disturbances, and that extraverts are happier because they have higher set points. The third class of explanations proposes that extraverts are more reactive or sensitive to positive stimuli and events than are introverts. For example, Larsen and Ketelaar (1991) showed that extraverts increase positive affect more than do introverts when watching a comedy or viewing pleasant photographs. Whether it explains extraverts' enhanced reactivity as due to cognitive mechanisms (Rusting \& Larsen, 1998), a stronger behavioral activation system (BAS; Eysenck, 1981), or the ratio between the BAS and the behavioral inhibition system (Gray, 1971), this third class of explanations suggests that a relatively fixed, structural difference in reactivity is responsible for the positive affect difference between extraverts and introverts (Carver, Sutton, \& Scheier, 2000; Davidson, 1998; Depue \& Collins, 1999; Gable, Reis, \& Elliot, 2000).

\section{The Extraversion-Positive Affect Relationship and the Ongoing Psychological Functioning of Individuals}

An important goal of psychology is to elucidate the ongoing, internal psychological functioning of individuals (Allport, 1937; Epstein, 1983; Lamiell, 1997; Larsen, 1989; Murray, 1938; Nesselroade, 1991; Pervin, 1994). That is, one of psychology's central tasks is to identify principles that describe the dynamics of how psychological elements internal to individuals vary and interact with each other. When the elements of psychological functioning are slow varying, changing over the course of months or years, these changes are known as development. Developmental processes concern the creation and maintenance of structures and systems. When the elements of psychological functioning are fast varying, changing within days, hours, or nanoseconds, the changes concern the operation of internal structures. That is, fast-varying psychological functioning describes how developed structures and systems operate within one individual (i.e., how parts of the mind interact with each other). In addition to describing such basic processes as perception, cognition, and motivation, this includes individuals' navigation of and interaction with the social world as well as self-regulation.

Being based on between-persons correlations, the extraversionpositive affect relationship describes the covariations of differences between people: The happier people are the ones who are more extraverted than others. The between-persons relationship has been very useful for identifying those who are happier than others, for demonstrating the importance of extraversion, and for provoking creative theorizing about processes that produce positive affect. However, making a between-persons relationship into one that is characteristic of fast-varying psychological functioning typically requires conceptual changes in the nature of the variables and the relationship, because (a) the variables must vary within one person rapidly and continuously and (b) such variance must be meaningful (Borkenau \& Ostendorf, 1998; Brown \& Moskowitz, 1998; Gable \& Reis, 1999; Larsen, 1989; Nesselroade, 1991; Stone, Shiffman, \& DeVries, 1999; Tennen, Affleck, Armeli, \& Carney, 2000; Valsiner, 1986). Sometimes such conceptual changes are not easily made consistent with current conceptions of the variables or of their relationship, and in such cases it is not expected that the between-persons relationship will characterize ongoing psychological functioning.

There are at least three reasons why the relationship between extraversion and positive affect is one of those not expected to characterize psychological functioning. First, traits are typically conceived of as structural, stable, and not varying rapidly within an individual (and perhaps not varying much even over years; McCrae \& Costa, 1990). Although an individual can act as though he or she has a different level of extraversion, it is not clear that this is the same as changing his or her level of extraversion. Second, principles of authenticity and concordance might imply that the content of an individual's behavior (e.g., whether it is extraverted or introverted) is less important than whether the behavior is in accordance with the individual's values or preferences. For example, many individuals prefer slow, relaxing activities to loud, exuberant ones.

Third, current explanations for the relationship between extraversion and positive affect rely on fixed, structural, and complex differences between extraverts and introverts. Because such structural, fixed features are the aspect of extraversion that affects positive affect and because complex, fixed structures cannot change rapidly within an individual, rapid variation in extraversion should not affect positive affect. Specifically, temperamental explanations posit that extraversion's role is to determine individuals' set points of happiness, around which other psychological processes may operate (Gross et al., 1998; Headey \& Wearing, 1989; Lykken \& Tellegen, 1996). Perturbations in happiness due to external events may change temporary levels of positive affect, but homeostatic principles will relatively rapidly return positive affect to the set point. Reactivity explanations posit that extraversion's role is prior to psychological functioning: It determines the strength of the reaction to positive events.

Of course, it must be the case that some within-person process or other is responsible for the robust between-persons relationship between extraversion and positive affect. That is, something must have been operating within at least some extraverts to produce their higher levels of happiness (or within introverts to produce their lower levels of happiness). However, current conceptions of extraversion, positive affect, and their relationship are most easily 
consistent with the notion that this process is already complete or involves variables other than rapid within-person variation in extraversion. Finding, in contrast, that the extraversion-positive affect relationship does characterize the ongoing psychological functioning of individuals would broaden considerably the relevance of the relationship, add to its credibility, and change the understanding of it. This finding would broaden the relevance by including the extraversion-positive affect relationship in the realm of basic processes of psychological functioning and by bringing it into the realm of self-regulation and navigation of the social world (Carver \& Scheier, 1999). This finding would add to the relationship's credibility by demonstrating that it really is extraversion that is essential to the relationship rather than some fact limited to extraverts. And this finding would change the understanding of the relationship by demonstrating that rapid variation in extraversion occurs, is meaningful, and needs to be referenced in explanations of the relationship.

\section{Traits as Density Distributions of States: State-Trait Isomorphism}

A recent model of traits as density distributions of states (Fleeson, 2001) predicts that the between-persons extraversion-positive affect relationship is directly characteristic of the ongoing psychological functioning of individuals. That is, just as variations across people in their dispositional levels of extraversion predict variations across people in their levels of positive affect, the density distributions model predicts that variations within a person over short periods of time in his or her level of extraversion do in fact occur and are predictive of variations in that person's level of positive affect. Thus, another reason for these studies is to test this model.

Building on the work of Allport (1937), Buss and Craik (1983), Cantor (1990), Epstein (1979), Fiske (1961), Larsen (1989), Mischel (1968), Moskowitz (1982), Nesselroade (1988, 1991), and others, the starting assumption of the density distributions model is that states can be described in the same way as are traits. That is, the way an individual is acting at the moment can be described in the same terms and with the same scales as are traits (e.g., just as individuals can be described as anywhere from low to high in conscientiousness, behaviors can be described as anywhere from low to high in conscientiousness). In three experience-sampling studies, then, participants described their behavior during the previous hour several times per day for 2 to 3 weeks, using adjectives commonly used for describing Big Five traits (Goldberg, 1992) and on 7-point scales. It was found that people routinely and regularly expressed all levels of all traits, forming distributions of states covering the entire 7-point scale. For example, the typical individual enacted behaviors at all levels of extraversion within a matter of days. Thus, extraversion does vary rapidly within a person, and it varies enough to potentially support covariation with positive affect within a person. It was also found that the location of an individual's distributions of states for a particular trait was highly stable, suggesting that the frequencies with which individuals enact various levels of states are a large part (but not all) of the nature of individual differences in traits.

Together, these findings suggest the principle of state-trait isomorphism, that states share many properties and consequences with traits. If a trait is in large part the distribution of states, then consequences of the trait may follow when the state is enacted.
That is, if the trait comes into existence through enactment of relevant states, then consequences of the trait may also come into existence through enactment of relevant states. Thus, state-trait isomorphism predicts that the extraversion-positive affect relationship previously revealed between persons may be characteristic of psychological functioning, that individuals' highs and lows of happiness may be predictable from their highs and lows in extraversion states, that structural or slow-moving aspects of individuals are not needed to explain the extraversion-positive affect relationship, and that one principle characterizing everyday navigation of the world is that more extraverted behavior brings with it more happiness than does more introverted behavior.

\section{How Many and Which Individuals Show an Extraversion-Positive Affect Relationship?}

The second purpose of this study is to determine the proportion of individuals who show a within-person relationship between extraversion and positive affect. The relationship may characterize the ongoing psychological functioning of some individuals yet not characterize all or even most individuals.

In fact, there are at least three versions of the general idea that the content, per se, of behavior is less important than is its relationship to the individual's dispositional personality. Authenticity (McGregor \& Little, 1998; Roberts \& Donahue, 1994; Sheldon et al., 1997), situational congruence (Emmons et al., 1986), and behavioral concordance (Moskowitz \& Côté, 1995) models share the propositions that behavior does influence affect but that individuals differ in how any given behavior influences affect. In particular, behaviors that are coherent in some form with the actor's broader personality influence affect most positively. Although these models differ importantly in the form of coherence and the reason for the positive consequences of coherence (e.g., familiarity, values, self-determination), they agree that the withinperson relationship between extraversion and positive affect should be strongest for those who are dispositionally extraverted.

The current studies test whether concordance or state-trait isomorphism better describes the within-person extraversion-positive affect relationship. Isomorphism is supported to the extent that most individuals show the relationship and that the strength of the relationship is not positively related to dispositional extraversion. In contrast, authenticity, situational congruence, and behavioral concordance are supported to the extent that fewer and mainly extraverted individuals show the relationship. It is important for us to be clear that this article does not test the general applicability of these models-each is likely to be applicable to some cases and not to others. In fact, a comprehensive description of personality necessarily includes a full account of the conditions under which states and traits are related according to different principles (Funder, 2001). The goal of the present research is to test whether state-trait isomorphism applies in at least one case-specifically, in the case of the important relationship between extraversion and positive affect. If state-trait isomorphism applies in at least one case, this means that it is one of the principles relating states to traits.

There are two additional reasons to determine the proportion of individuals for whom the extraversion-positive affect relationship characterizes their ongoing psychological functioning. First, the greater is the proportion of individuals who show the extraversionpositive affect relationship, the greater is the credibility of the 
relationship. If only a portion show it, the relationship can be dismissed not as a general description of personality and traits but as a peculiarity to certain individuals (e.g., those who highly value socializing). Second, the greater is the proportion of individuals who show the relationship, the wider is the potential application of the relationship as an intervention.

\section{Overview of Studies}

Three studies examine the within-person relationship between extraversion and positive affect. Study 1 uses experience-sampling methodology: Participants reported their current level of extraversion and positive affect five times per day for 13 days. This study investigates whether momentary increases in extraversion are associated with momentary increases in positive affect. Study 2 uses a diary method: At the end of every week for 10 weeks, participants reported their levels of extraversion and positive affect during the previous week. Besides replicating Study 1 with a different methodology, Study 2 addresses whether sustained increases in extraversion, in addition to momentary increases, are also associated with increases in positive affect. Study 3 is an experiment designed to test whether the effect could be (a) manipulated and (b) found within a fixed, controlled situation. Participants were instructed to act extraverted or to act introverted during a 10-min discussion; afterward, they reported their levels of positive affect during the discussion.

Investigating the extraversion-positive affect relationship across three distinct methodologies should provide a relatively definitive case about the relationship. This is important for personality psychology for examining whether this crucial relationship is characteristic of the ongoing psychological functioning of individuals, for testing the density distributions model of traits, and for exploring the practical implications that one can increase positive affect by acting more extraverted.

\section{Study 1}

\section{Method}

Participants. Forty-six students participated in the experiment in partial fulfillment of the requirements for an introductory psychology course. Four participants provided fewer than 20 valid reports and so were excluded from all analyses. Portions of Study 1 have been previously published (Fleeson, 2001).

Procedure. Five times per day for 13 days, participants described how they had been acting and feeling during the previous hour. These reports were completed on a regular schedule, every $3 \mathrm{hr}$ (noon, 3 PM, 6 PM, 9 PM, and midnight) and took about 1 to $2 \mathrm{~min}$ to complete. Reports were completed on Palm Pilots, hand-held computers about the size of a calculator. Each question was printed on a small screen, and participants responded by pressing a number with a plastic stylus. To encourage timely completion, we asked participants to download their data every 2 days, and those who missed a download were contacted.

The first report occurred during a 45-min introductory session. The procedure was explained, questions were answered, and participants chose code names to make their anonymity salient. The unique nature of this study, that it investigated a complete picture of 2 weeks of each individual's life, was stressed as well as that it was important that they complete as many reports as honestly as possible. At the end of the introductory session, participants were invited to withdraw for partial credit if they felt the study was too intrusive. Participants also completed a standard assessment of the Big Five during this introductory session.
The response rate was within normal range for such experiencesampling studies. For the included 42 participants, the mean number of reports was 50.6 of 65 possible (78\%), and the median was 53.5 reports (82.3\%), with a range of 23 to 63 reports. Participants had been instructed to miss a report if it would be a major inconvenience to complete (e.g., while they were driving, taking an exam, sleeping). Participants were also told they could complete a report up to $3 \mathrm{hr}$ later than the scheduled time but to nonetheless describe the scheduled hour. Reports were also missed because participants forgot or had computer problems. In the interest of maintaining data quality, we excluded completed reports if they did not meet strict criteria. First, reports that contained four or more missing values or at least $85 \%$ identical responses were excluded (e.g., the participant recorded 1s for all responses). Second, an advantage to Palm Pilots is that they surreptitiously record the date and time of completion. Thus, all events completed at least $1 \mathrm{hr}$ earlier or more than $3 \mathrm{hr}$ later than the scheduled time were excluded, which guaranteed that all reports were completed close in time to the described behavior. In total, 237 of the 2,126 reports were excluded for one of these reasons $(11 \%)$.

Materials. The daily reports were in the same format as traditional adjective-based Big Five and affect scales, with the exception that rather than describing themselves in general, participants described their behavior and emotion during the previous hour (e.g., "During the previous hour, how talkative were you?"). Extraversion and positive affect were each represented by four items (extraversion: "talkative," "energetic," "assertive," "adventurous"; positive affect: "excited," "enthusiastic," "proud," "alert"). The Big Five are appropriately assessable with a large variety of adjectives (Goldberg, 1992); for this study, adjectives were chosen that (a) loaded on the correct factor in Goldberg (1992) either alone or as part of a bipolar item or in De Raad, Hendriks, and Hofstee (1994), (b) together represented the breadth of a factor, (c) were easily used to describe behavior, and (d) contained no emotion words (to avoid redundancy with the affect scales). For affect, eight representative items were chosen from the Positive and Negative Affect Schedule (PANAS; Watson, Clark, \& Tellegen, 1988). Items were presented in Goldberg's (1992) opaque order: The five traits were cycled through, with one adjective per cycle in the above-listed order, followed by alternating negative and positive affect adjectives. All adjectives were responded to on scales ranging from 1 to 7 , with higher numbers meaning that the adjective was more descriptive. We computed scale scores for extraversion and positive affect for each report by taking the mean of the corresponding four items. Thus, each participant produced about 45 descriptions of how extraverted he or she was and how much positive affect he or she experienced in 45 different 1 -hr periods. Participants also indicated which situation they were in the majority of the hour, choosing from class, studying, exercise or sports, work or volunteer activities, party, dorm, meal, or other.

Reliability was calculated across all included reports and was found to be similar to reliability of Big Five traits and affect scales in previous work: for extraversion, Cronbach's $\alpha=.72$; for positive affect, $\alpha=.80$.

At the end of the introductory session, participants also completed a standard assessment of the Big Five, describing what they are like in general. The same adjectives plus "shy" (reverse scored) and "bold" were used in this assessment.

\section{Results and Discussion}

Descriptives and suitability of within-person data. Each participant was in some ways equivalent to a complete study, providing multiple measurements of extraversion, multiple measurements of positive affect, and a measure of covariation between them. Thus, it is important to examine the data quality separately for each participant, to ensure that the variables are reasonably distributed for each individual. For example, Figure 1 shows a scatterplot of 1 participant's extraversion and positive affect scores. Each point represents this individual's extraversion and positive affect during 1 hour. For extraversion and positive affect, 


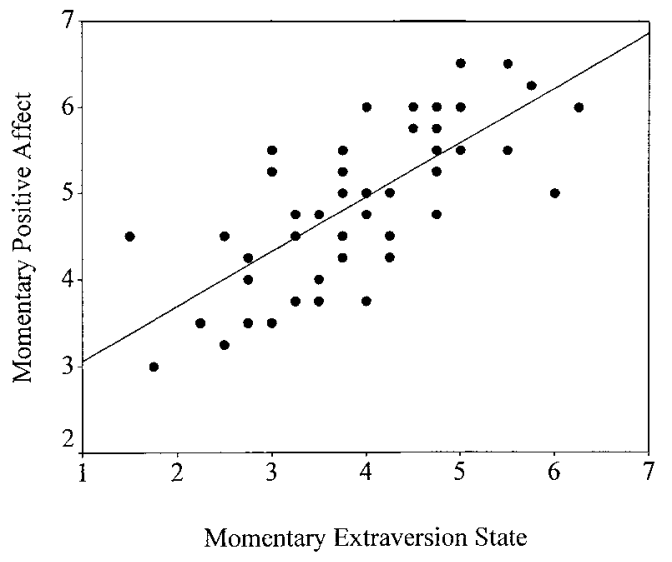

Figure 1. One participant's distribution of extraversion states and positive affect states over 2 weeks. Each point represents $1 \mathrm{hr}$. The regression slope of .63 means that this individual's positive affect increased by .63 for every point his or her extraversion increased.

this individual's means were 3.97 and 4.94, and standard deviations were 1.01 and 0.90 , respectively, demonstrating that this individual had enough fast-moving variability in extraversion to support the possibility of covariation between extraversion and positive affect. This participant also had normal distributions, with no outliers.

Corresponding analyses conducted separately for each individual revealed extraversion means between 2.47 and 5.35, positive affect means between 2.24 and 6.21, extraversion standard deviations between 0.65 and 1.80 , and positive affect standard deviations between 0.58 and 1.73 . Thus, no participant suffered from floor or ceiling effects, all participants varied sufficiently in both extraversion and positive affect, and most participants varied routinely from very introverted to very extraverted. All participants but one showed relatively normal distributions with no extreme outliers, and that one participant's outlier was removed. (Additionally, the following analyses produced similar results when a stricter criterion was used for outliers: removing all reports more than three standard deviations away from that individual's mean.)

Within-person relationships between extraversion and positive affect. The primary question in Study 1 is whether individuals increase in positive affect, in comparison with themselves, when they increase in extraversion. Every individual has moments when he or she is happier than at other moments; the question is whether those moments are the same as ones in which the individual is acting more extraverted than he or she normally does. The important point to be stressed is that each individual is his or her own comparison standard: Do that person's relatively greater moments of positive affect correlate with his or her greater levels of extraversion?

We calculated a regression for each participant separately, predicting positive affect from extraversion, with the resulting beta indicating the degree to which that participant's occasions that had greater positive affect were also those with greater extraversion. For example, Figure 1 shows the regression line for one participant, whose unstandardized beta was .63, meaning that, for every point that two of his or her occasions differed on extraversion, those occasions differed .63 points on positive affect. Thus, this is one individual for whom the within-person relationship between extraversion and positive affect holds.
Unstandardized betas were calculated for each participant, and Figure 2 shows the distribution of betas in the sample. Each point represents one individual's relationship between extraversion and positive affect, and the average beta across individuals was .66, meaning that the typical individual improved in affect at the same times he or she increased in extraversion. A one-sample $t$ test revealed that this average beta is significantly greater than zero, $t(41)=23.51, p<.001$, meaning that it is beyond the power of chance to have produced it. More impressive, however, is that no single participant had a negative relationship, and the beta closest to zero was $.20{ }^{1}$ That is, every single individual was happier when he or she acted extraverted than when he or she acted introverted, and the extraversion-positive affect relationship was characteristic of the ongoing psychological functioning of individuals. Furthermore, the psychological functioning of a high proportion of individuals was characterized by this relationship.

Individual differences in the relationship between extraversion and positive affect. Although all participants' ongoing, internal psychological functioning was characterized by a positive relationship between acting extraverted and feeling positive affect, individuals differed in the strength of the relationship, as shown in Figure 2. We conducted split-half reliability analyses to determine whether these individual differences were stable characteristics of individuals rather than due to error. Each individual's data were divided into two even-odd halves, and extraversion-positive affect betas were calculated for each half. The correlation between the two halves was $.46(p<.01)$, indicating that those individuals who demonstrated a stronger than typical relationship between extraversion and positive affect in one half of the data also demonstrated a stronger than typical relationship in the other half of the data. The only way to account for this is that individuals differ reliably in the relationship - that the strength of the relationship between extraversion and positive affect is a feature of individuals.

To test whether concordance applies to this relationship, we correlated individual differences in strength of the extraversionpositive affect relationship with extraversion scores from a typical questionnaire assessment. The correlation between dispositional extraversion and the beta was $r(41)=-.35, p<.05$. That is, extraverts do not enjoy acting extraverted any more than do introverts. In fact, introverts were the ones who particularly increased in positive affect at those times they increased in acting extraverted, contrary to predictions of authenticity or concordance.

Within-situation analyses. In addition to varying in extraversion, individuals also varied in the situational contexts of their actions. Individuals are likely to vary both in their extraversion level and in their positive affect level across different situation types, and such covariation may produce a spurious relationship between extraversion and positive affect. This is not a central concern of this article, as the main point is to follow as closely as possible the between-persons findings, except using within-person methodology.

Nonetheless, we have available a crude control for situation. Each participant indicated which of the eight situation types described his or her current situation at the time of each report. Regressions were calculated separately for each situation within

\footnotetext{
${ }^{1}$ One participant who completed only 14 valid reports and thus was excluded from analyses showed a negative relationship of -.15 between extraversion and positive affect.
} 


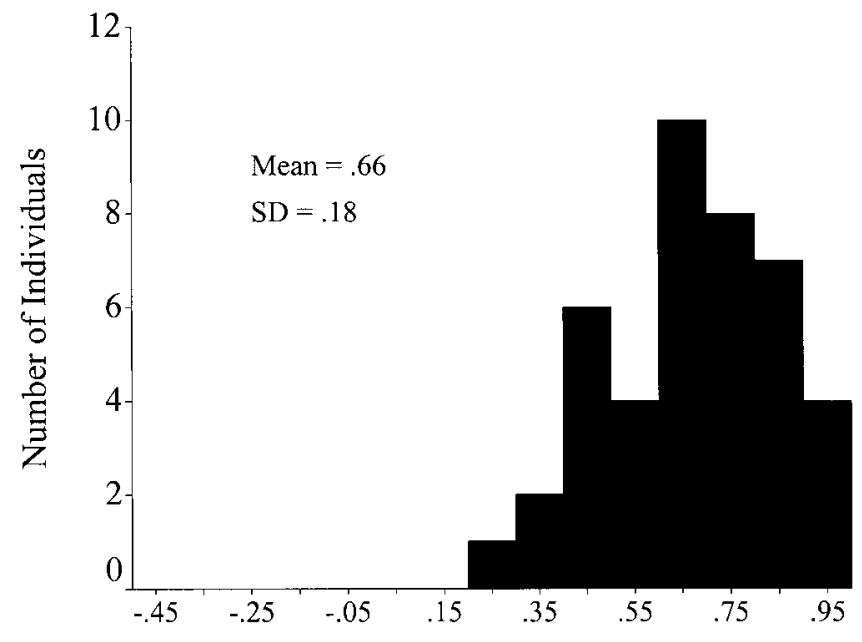

Beta Predicting Positive Affect from Extraversion

Figure 2. Distribution of within-person betas predicting positive affect from extraversion. Each participant contributed one beta, representing how much his or her positive affect increased when his or her level of extraversion increased in a given hour. No participant had a negative beta, and the closest to zero was 20 .

each participant. Thus, each regression considered only reports that occurred in the same situation type and evaluated whether one individual's positive affect varied with his or her extraversion variations within that situation type alone. Figure 3 shows the resulting betas for each situation, averaged across all participants. (Regressions were calculated for a given participant for a given situation only if he or she reported being in that situation at least five times; thus, the number of participants differed across situation types, and the estimates were less reliable for some individuals than for others.) For example, the bar for in class indicates that the typical individual had a .75 relationship between extraversion and positive affect when we considered only those hours in which he or she was in class, such that the classes in which he or she was happier were those classes in which he or she acted more extraverted. One-sample $t$ tests revealed that all betas were significantly greater than zero except for the beta in exercise and sport situations $(p=.06)$. Thus, acting more extraverted was associated with enhanced positive affect regardless of whether the individual was in class, studying, working, at a party, in a dorm, or at a meal. However, these conclusions can be considered only tentative because of the small number of reports for some situations for some individuals.

Simultaneous multilevel models. It is possible to estimate separately for each individual the precision of his or her estimated relationship between extraversion and positive affect and to take this into account when calculating group statistics. This should result in more reliable estimates of the typical individual's extraversion-positive affect relationship and of the effect of dispositional extraversion on that relationship. In addition, it provides estimates of several variations and explained variations. We chose to estimate by using simultaneous multilevel modeling with restricted maximum likelihood estimation (Singer, 1998).

Results from such analyses provide verification of the above ordinary least squares results. First, state positive affect was pre- dicted from state extraversion, with intercepts and slopes allowed to vary randomly across individuals. State extraversion had a beta of .68 $(p<.001)$, verifying that the typical individual experiences a moderately strong relationship between his or her current state positive affect and his or her current state extraversion. Of the explainable variation within individuals in levels of state positive affect (1.28), state extraversion explained 48\% (0.62). Furthermore, variation across individuals in the strength of the relationship was both small and significant $(p<.01)$, verifying that individuals differed reliably in the relationship between extraversion and positive affect but that few individuals approached a zero relationship.

Next, dispositional extraversion from the questionnaire and the interaction between dispositional extraversion and state extraversion were added to the model. The interaction was significant $(\beta=$ $-.05, p<.05$ ), verifying that more extraverted individuals had weaker within-person relationships between state extraversion and state positive affect. However, adding dispositional extraversion to the model did not explain any between-persons variation in average levels of positive affect (in fact, unexplained variation increased from 0.30 to 0.32 ). A study specifically designed to detect between-persons relationships may well find that some of that 0.32 between-persons variation in positive affect is explained by dispositional extraversion.

Finally, the ability to adjust for varying reliability and precision is particularly important in the within-situation analyses because those analyses suffered from fewer available reports. Separately within each situation, multilevel analyses predicted state positive affect from state extraversion, with slopes and intercepts allowed to vary randomly. For all situations except at a party, the average individual's slope was greater than .60 and significant at the $p<$ .001 level (the analyses failed to converge for party).

In sum, the multilevel model provides compelling verification for the results presented earlier as well as adds additional information about variation and explained variation.

\section{Study 2}

Study 1 shows that the relationship between extraversion and positive affect holds within person as well as between persons.

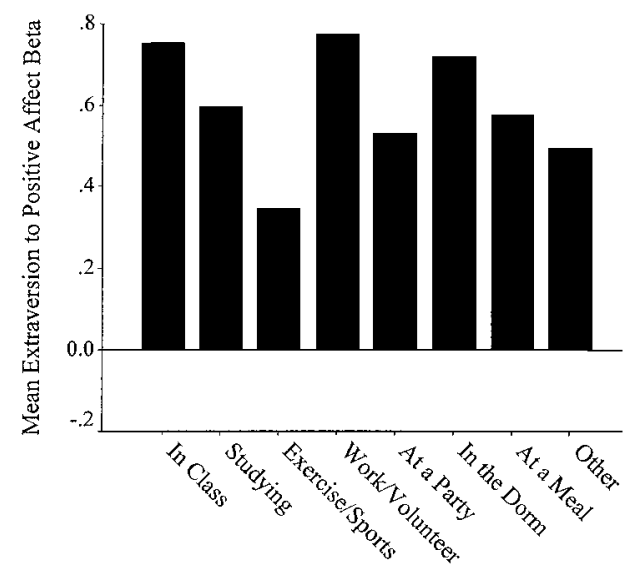

Figure 3. Mean betas within each of eight different situation types. Holding situation type constant by conducting analyses on reports from only one situation type at a time revealed positive within-person relationships between extraversion and positive affect for each situation type. 
Thus, Study 1 provides evidence (a) for some degree of trait-state isomorphism and (b) that the extraversion-positive affect relationship describes not only differences between individuals but also a process that is ongoing throughout daily life within each individual.

Precisely because Study 1 is targeted at this ongoing process, it investigates rapid (hourly) changes in extraversion and in positive affect. It is possible, however, that hourly changes are too rapid, and although short-term bursts of extraversion may be associated with positive affect, such increases in positive affect are neither sustainable nor genuine. Study 2 investigates the same phenomena but uses a diary methodology to assess extraversion and positive affect over the previous week at weekly intervals to test whether longer term affect is also associated with longer term state variation in extraversion.

\section{Method}

Participants. Sixty-three students participated in the experiment in partial fulfillment of the requirements for an introductory psychology course. The 57 who completed all 10 weeks' reports were included in the analyses.

Procedure. Every Monday or Tuesday for 10 consecutive weeks, participants reported to the same location and described their affect and behavior during the previous week. Participants who did not come to the location were called to come in on the immediately following Wednesday.

During an initial session, participants were instructed as to the procedure and also completed a measure of the Big Five and the PANAS, both referring to how they are in general. During the final week, participants completed the generalized Big Five and PANAS measures again. Completion of materials was excellent. Fifty-seven participants (93\%) completed all 10 weeks' materials.

Materials. The weekly reports were in the same format as traditional adjective-based Big Five and affect scales, with the exception that rather than describing themselves in general, participants described their behavior and emotion during the previous week. Extraversion was represented by 5 items ("talkative," "assertive," "shy," "bold," "energetic"), and positive affect was described by 10 items ("excited," "interested," "strong," "enthusiastic," "proud," "alert," "inspired," "determined," "attentive," "active"). Participants responded to all adjectives on scales ranging from 1 to 7, with higher numbers meaning that the adjective was more descriptive; we computed scale scores for extraversion and positive affect for each report by taking the mean of the corresponding items.

Reliability was calculated across all included reports and was found to be similar to reliability of Big Five traits and affect scales in previous work: for extraversion, Cronbach's $\alpha=.67$; for positive affect, $\alpha=.88$.

\section{Results and Discussion}

Each participant's data were examined separately for suitability for analyses. The average participant's within-person standard deviations across the 10 weeks were 0.59 for extraversion (range $=0.25$ to 1.24 ) and 0.60 for positive affect (range $=0.17$ to 1.19 ), meaning that there was enough variability across weeks in how extraverted each individual acted and how much positive affect each individual experienced (a few individuals showed relatively little variability, reducing the likelihood that we would find a substantial relationship between extraversion and positive affect for those individuals). No reports had extraversion or positive affect scores more than 2.5 standard deviations from their reporter's mean, so no outliers were removed, and the data were considered suitable.
We calculated a regression for each participant separately, predicting his or her positive affect variance across the 10 weeks from his or her extraversion variance across the 10 weeks. Figure 4 shows a histogram of resulting betas. Results are very similar to those of Study 1, in that nearly all participants had a positive relationship: Weeks in which they were happier were weeks in which they acted more extraverted. The average beta was .53 , which was significantly greater than zero, $t(56)=9.82, p<.001$. Only 6 participants of the 57 showed a negative beta $(-.29,-.12$, $-.06,-.03,-.02$, and -.02$)$. Given the smaller number of occasions over which these regressions were calculated, it is possible that these represent error (i.e., unusual weeks for those 6 participants).

In sum, longer term increases in state extraversion were also associated with longer term increases in positive affect. The within-person relationships are not explainable as short term or inauthentic flukes.

Split-half reliabilities were used in Study 1 to test whether individuals differed reliably in the strength of the relationship between extraversion and positive affect, but they are not reasonable to calculate in Study 2, with only 10 occasions per participant. However, dispositional extraversion was found to be unrelated to the strength of the within-person relationship between extraversion and positive affect $(r=.00, n s)$.

Because of the small number of reports per individual (i.e., 10), multilevel models that take into account precision of within-person estimates are particularly important. Such analyses verified the above results. First, weekly positive affect was predicted from weekly extraversion with randomly varying intercepts and slopes. The beta for extraversion was $.59(p<.001)$, verifying that the typical individual had a positive relationship between extraversion and positive affect across weeks. The model including dispositional extraversion and its interaction with state extraversion did

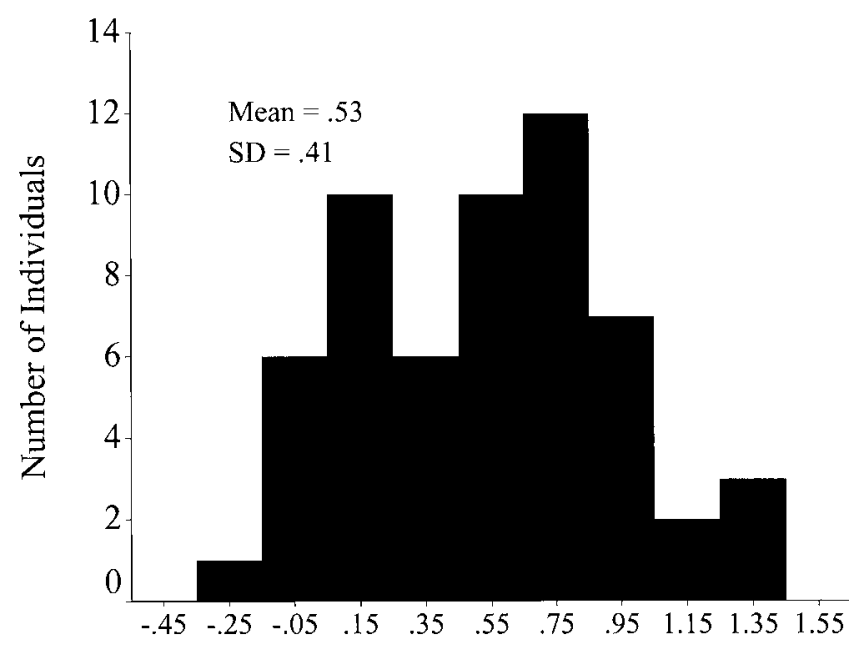

Beta Predicting Positive Affect from Extraversion

Figure 4. Distribution of within-person betas predicting positive affect during a week from extraversion during the same week. Each participant contributed one beta, representing how much his or her positive affect increased when his or her level of extraversion increased in a given week. Nearly every participant was characterized by a positive relationship across 10 weeks. 
not produce a significant interaction $(\beta=.05, p=.41)$, suggesting that extraverts do not benefit more than do introverts from acting extraverted. In sum, although each participant contributed only 10 reports, the power of the study comes from multiplying that by 57 participants for a total of 570 reports. However, replication of this finding across more weeks is needed for a convincing case.

\section{Study 3}

Studies 1 and 2 demonstrate that the extraversion-positive affect relationship characterizes ongoing within-person processes that occur over both very rapid (hourly) state fluctuations and less rapid (weekly) state fluctuations. However, these relationships may be due to variations in situations. That is, these relationships may be byproducts of the fact that situational variation leads to variation in affect and also to variation in extraversion. For example, social situations likely increase positive affect (Cantor et al., 1991; Fleeson \& Cantor, 1995) and also increase extraverted behavior. Although Study 1 shows that the relationship was evident even within each of several situation types, those were only suggestive and supplementary analyses rather than the main point of Study 1 . Furthermore, it is possible that more subtle variations in situations were still present and responsible for the extraversion-positive affect relationship.

The final study investigates whether the within-person relationship can be demonstrated in a fixed situation. Experimental methodology was used; participants came to the lab and participated in a fixed situation, and they were instructed to act either extraverted or introverted. If positive affect varies as a result of instruction while the situation is held constant, then it is clear that the extraversion-positive affect relationship is not due to situational variation.

\section{Method}

Participants. Forty-seven students participated in the experiment in partial fulfillment of the requirements for an introductory psychology course. Only participants whose score on a mass-testing extraversion scale was in the top or bottom $20 \%$ of all mass-testing participants (i.e., less than 4.38 or greater than 5.62) were invited to participate (one individual with a score of 5.50 also participated; one individual completed the experiment twice, so only the first participation was included, reducing the sample size from 48 to 47 ).

Design. The study uses a 2 (state extraversion) $\times 2$ (dispositional extraversion) design. State extraversion was a counterbalanced, withinperson variable. Dispositional extraversion was a between-persons variable.

Procedure. Participants arrived at the laboratory in groups of 3 , sat at a small, semicircular table, and were individually, independently, and randomly assigned to act extraverted or introverted by questionnaire distribution. Participants first read instructions to act extraverted or instructions to act introverted (depending on their assigned condition) during a following group discussion. Participants then engaged in the group discussion for up to $10 \mathrm{~min}$. At the end of the group discussion, each participant rated his or her own behavior and affect during the discussion and attitudes toward the discussion, followed by ratings of the other participants' behavior and affect during the discussion. Participants were then assigned to the complementary state condition and engaged in a second group discussion, followed by ratings of their own behavior and affect and ratings of others' behavior and affect. Thus, each participant participated in both an instructed extraversion and an instructed introversion condition, and the order was randomly determined for each participant without regard for the instructions to other participants in the same session.
Materials. It was important to keep the manipulated states as close as possible to the self-reported states used in Studies 1 and 2. Thus, instructions were phrased in terms of specific marker adjectives of extraversion. We manipulated extraversion by instructing participants to act bold, talkative, energetic, active, assertive, and adventurous. We manipulated introversion by instructing participants to act reserved, quiet, lethargic, passive, compliant, and unadventurous. In addition, to remind participants of their capability of acting in these ways, we asked them to think of a recent time in which they did act in those ways and to answer four questions about that time with about one sentence each. (Given the results of Studies 1 and 2, we presumed that all participants had acted highly extraverted and highly introverted on at least one occasion each during the recent week.)

In the first discussion, participants rank ordered the usefulness of 10 items available after an airplane crash in Northern Minnesota (a standard task; e.g., Haunschild, Moreland, \& Murrell, 1994). In the second discussion, participants rank ordered 10 possible solutions to the parking problem on campus. Both tasks were ambiguous and interesting, so as to encourage involvement and discussion.

After each discussion, participants rated their own behavior and affect, their attitudes toward the discussion, and others' behavior and affect. Behavior was assessed with 29 adjectives, 8 of which assessed extraversion ("energetic," "assertive," "lethargic," "talkative," "shy," "bold," "passive," and "adventurous"). Additional adjectives for the other Big Five traits were included as distractors. For each adjective, participants indicated how well it described the way they "acted during the discussion." Affect was rated on the PANAS (Watson et al., 1988), with the instruction that participants rate the "extent you have felt this way during the discussion." We created 11 items to assess participants' attitudes toward the discussionspecifically, to assess how much they enjoyed the discussion (e.g., "I had moments of fun during the discussion," "The discussion was enjoyable"). Participants responded to these items on 7-point scales. Ratings of others' behavior and affect were identical to ratings of participants' own behavior and affect, except that participants first indicated which other person they were rating (identified by the letter $A, B$, or $C$ on the table) and then rated "how well the adjective describes the way that discussant acted during the discussion" or "to what extent that discussant felt this way during the discussion." Some participants were confused by the rating procedure (e.g., rated the same other twice or ambiguously identified the other), and 36 of the 188 sets of observer ratings were not included because of participant mistakes. The two observers' ratings were averaged to form a composite rating; observer agreement was reasonably high: $r(61)=.82, p<.001$, across conditions; $r(29)=.23, n s$, in the extraversion condition; and $r(32)=.68, p<.001$, in the introversion condition.

\section{Results and Discussion}

A 2 (state extraversion) $\times 2$ (dispositional extraversion) analysis of variance (ANOVA) on positive affect during the discussion revealed a main effect of state extraversion, $F(1,45)=150.11$, $p<.001$, but no effect of dispositional extraversion, $F(1$, $45)<1.00$, nor an interaction, $F(1,45)<1.00$. Thus, as predicted, acting extraverted increased the amount of positive affect during the discussion $(M=5.16, S D=1.14)$, as compared with the amount of positive affect participants experienced when acting introverted $(M=2.34, S D=0.97)$, and this effect did not depend on the dispositional extraversion of the person acting that way. Note that this effect was over two and a half standard deviations.

Counterbalancing allowed us to test for order effects; a 2 (state extraversion) $\times 2$ (dispositional extraversion) $\times 2$ (order) ANOVA on positive affect revealed a small three-way interaction, $F(1,43)=8.63, p<.01$. As plotted in Figure 5, follow-up tests indicated a significant two-way interaction between order and state extraversion for dispositional introverts, $F(1,21)=16.67, p<$ .01 , but not for dispositional extraverts, $F(1,22)<1.00$. This 


\section{Introverts}

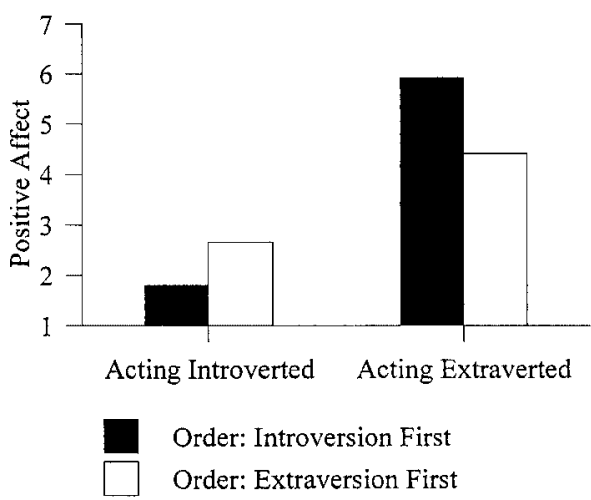

Extraverts

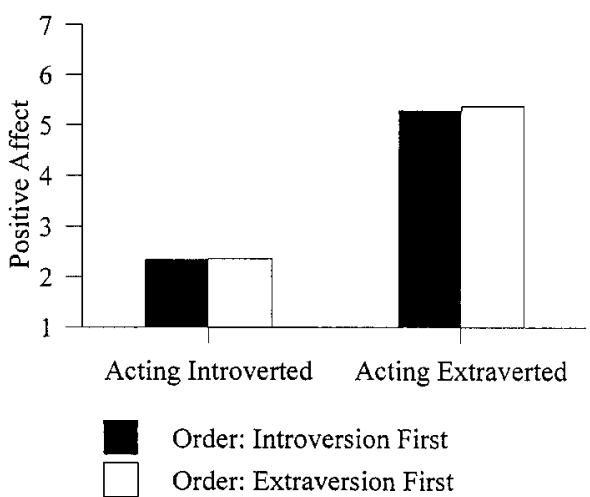

Figure 5. Three-way interaction between dispositional extraversion, instruction to act extraverted or introverted, and order of instruction. Dispositional introverts benefited from acting extraverted somewhat more in Session 2, whereas dispositional extraverts benefited from acting extraverted as much in Session 1 as in Session 2. However, the central finding is that acting extraverted had a very large effect on positive affect during the discussion.

interaction for dispositional introverts means that they benefited somewhat more from acting extraverted after they had first acted introverted, whereas they benefited somewhat less when they had to act extraverted from the beginning. This finding may hint at a kind of congruence effect, such that introverts are able to benefit as much as extraverts from acting extraverted but that it requires at least minimal familiarity with the situation before they receive the full benefit. It may also be a contrast effect, such that introverts are able to benefit from extraversion more when they have the clear contrast of just having acted introverted. However, Figure 5's main point is that these order effects are small as compared with the overwhelming finding that acting extraverted had a very large effect on positive affect during the discussion.

Attitudes toward the discussion. A 2 (state extraversion) $\times 2$ (dispositional extraversion) ANOVA on attitudes toward the discussion also revealed a main effect of state extraversion, $F(1$, $45)=79.27, p<.001$, but no effect of dispositional extraversion, $F(1,45)=2.65, n s$, nor an interaction, $F(1,45)<1.00$. That is, acting extraverted also increased participants' favorability toward the discussion $(M=5.18, S D=1.18)$ as compared with acting introverted $(M=3.08, S D=1.23)$.

Manipulation check. We repeated a 2 (state extraversion) $\times 2$ (dispositional extraversion) ANOVA with self-ratings of extraversion to check whether participants indeed acted in the ways they were instructed to, and this ANOVA revealed a main effect of state extraversion, $F(1,45)=195.09, p<.001$, but no effect of dispositional extraversion, $F(1,45)=1.34, n s$, nor an interaction, $F(1,45)<1.00$. Thus, individuals acted more extraverted in the extraverted condition $(M=5.71, S D=1.08)$ as compared with in the introverted condition $(M=2.21, S D=0.98)$.

Observer ratings. Observer ratings were used as a test of the robustness of the findings both (a) to possible demand characteristics and (b) in terms of the findings' visibility even to outsiders. A 2 (state extraversion) $\times 2$ (dispositional extraversion) ANOVA on observer-reported positive affect revealed a main effect of state extraversion, $F(1,38)=97.30, p<.001$, no effect of dispositional extraversion, $F(1,38)<1.00$, and no interaction, $F(1,38)<1.00$. A 2 (state extraversion) $\times 2$ (dispositional extraversion) ANOVA on observer-reported extraversion revealed a main effect of state extraversion, $F(1,37)=20.29, p<.001$, but no effect of dispositional extraversion, $F(1,38)<1.00$, nor an interaction, $F(1$, $38)<1.00$. Thus, observers also reported that participants were happier when instructed to act extraverted $(M=5.28, S D=0.98)$ as compared with when instructed to act introverted $(M=2.63$, $S D=1.26)$.

\section{General Discussion}

The typical interpretation of the between-persons extraversionpositive affect relationship is correctly comparative across persons: Individuals who are more extraverted than others also have more positive affect than those others (Lucas et al., 2000). That is, a change in extraversion requires going from one person to another. Translating to a within-person correlation would require that changes in one individual's extraversion are associated with changes in that same individual's positive affect. Mathematically, nothing requires such a translation. More important, the conceptual implications of such a translation argue against it for many reasons, including that (a) something structural or fixed about extraverts seems responsible for their increased happiness, (b) becoming happier seems more difficult than simply acting more extraverted, (c) the effect of acting extraverted might seem to depend on personal preferences or values, (d) state extraversion might be very different from trait extraversion, and (e) variation in external variables, such as circumstance and fortune, seem so important in producing variation in happiness that it is hard to believe that a primary determinant of variation in daily happiness originates internally. Thus, translating this to a within-person process is typically taken to mean that, at most, changes in one individual's trait extraversion over years might change that individual's overall level of positive affect.

However, there is an entire domain of psychological functioning left out by this interpretation-the domain of navigation of the environment, of self-regulation, and of interaction with others. When researchers do link the extraversion-positive affect relationship to this domain of psychological functioning, they invoke 
proxy processes such as changes in amount of socializing or how individuals interpret events (e.g., Gable et al., 2000). That is, personality is taken as relevant to process only as a predictor of process, whereas nonpersonality variables are recruited to constitute the process itself (Tennen, Suls, \& Affleck, 1991). In contrast, straightforwardly translating the correlation to one that is characteristic of within-person variation would mean that each individual changes in extraversion rapidly (e.g., hour to hour) and that positive affect changes within that individual in step. The present findings show that this latter translation is surprisingly warranted and that the extraversion-positive affect relationship is so pervasive that it characterizes even individuals' ongoing and fastvarying psychological functioning.

Study 1's experience-sampling methodology shows that it is possible to predict an individual's positive affect at all times from the extraversion of his or her current behavior, regardless of whether he or she is purposefully or more naturally acting introverted, extraverted, or anywhere in between. Furthermore, every participant's psychological functioning was characterized by the covariation of extraversion and positive affect. This finding of general applicability corrects the misperception of introverts as being happiest during nonexuberant activity and also increases both the credibility and the importance of the extraversionpositive affect relationship by showing that it is a general process not limited to extraverts but characteristic of possibly all individuals' ongoing psychological functioning. Study 2's diary methodology provides preliminary evidence that the phenomenon is true not only for hourly but also for weekly ups and downs of happiness and that the relationship applies to sustained increases in extraversion as well as to short-term bursts. However, replication across more than 10 weeks is suggested. Study 3's experimental methodology discounts situational explanations, showing the phenomenon in a fixed and controlled situation.

\section{Taking States Seriously}

States is a word about which personality psychologists have disagreed: Some have reserved the use for the particular content of affect, such that states can refer only to affective terms such as happy, anxious, or sad. In contrast, we agree with those who have limited the word to refer to formal properties rather than to content: States are psychological entities that are short-lived, continuous, and concrete, as opposed to long-lived, discontinuous, and abstract (Cattell, Cattell, \& Rhymer, 1947; Fridhandler, 1986; Nesselroade, 1988; Patrick \& Zuckerman, 1977; Spielberger, Lushene, \& McAdoo, 1977). Thus, states can apply to trait content just as traits can.

The current findings support the hypothesis that states can take on important properties of traits, that states and traits are isomorphic in at least some regards. Indirectly, then, the findings also support the density distributions model of traits. Specifically, part of having a trait is simply acting that way (slightly) more often, and acting a certain way is similar to being that way. This is not to say that faking extraversion is as good as being extraverted, but genuinely acting extraverted may be equivalent to being extraverted. In regard to positive affect, there may be nothing special about being extraverted that one cannot gain simply by acting extraverted. In contrast to isomorphism and because of the importance of personal integrity, familiarity, and comfort, congruence theories suggest that states are not equivalent to traits and that the meaning of a given state depends on the traits of the actor (McGregor \& Little, 1998; Roberts \& Donahue, 1994; Sheldon et al., 1997). For example, although both agreeable and disagreeable individuals find being disagreeable unpleasant, disagreeable individuals do not find it quite as unpleasant as agreeable individuals find it (Côté \& Moskowitz, 1998; Moskowitz \& Côté, 1995). We are willing to bet that isomorphism and congruence are each true under different conditions. In fact, recent support both for concordance and for isomorphism calls for more research to determine when and under what conditions each principle is more accurate and to establish the personality dynamics of behavior and traits.

The findings supporting isomorphism may also have important clinical implications. At a general level and in line with the "doing" view of personality, as presented by Cantor (1990), the findings suggest that individuals have flexibility and opportunity to act in different ways and bring about personally desired consequences. That is, positive affect was predicted by what the individuals did regardless of what (traits) they had. Thus, individuals are not limited to a single, set personality or to the consequences of their long-standing traits. At a more specific level, the robust between-persons relationship between extraversion and positive affect has always promised a possible clinical intervention for increasing positive affect, that individuals can increase their positive affect by increasing their extraversion. The present studies show for the first time that a rather simple intervention of encouraging individuals to act more extraverted may be particularly successful. Before it can be established as clinically useful, the causality of this relationship and its applicability to the clinical context certainly need to be established. But the first and critical step, showing that this process does occur within individuals, has now been taken. Note that this intervention is relevant not only to those suffering from a lack of positive affect (e.g., depressed individuals) but also to positive psychology (Sheldon \& King, 2001). Less attention has been paid to interventions that enhance positive well-being than to those that reduce negative well-being, and the extraversion-positive affect relationship is one that would support enhancing positive well-being (Ryan \& Deci, 2001; Seligman \& Csikszentmihalyi, 2000)

Isomorphism may provide many useful opportunities for personality psychologists. Variation in states is easier to observe and more rapid than is variation in traits. For example, it would take many years and many individuals to observe the within-person relationship between trait extraversion and positive affect; observing sufficient states takes much less time (although it does require extensive sampling of each individual's daily behavior). Thus, personality research into the processes involving traits may be greatly facilitated by observations of variation in states. Furthermore, taking states as potentially causal allows personality psychologists to focus on variables of interest to personality in the explanations of process rather than relying on external variables such as situations. Finally, a decades-old problem in personality psychology has been the difficulty in using the methods of experimental control that efficiently enhance claims of internal validity (Cronbach, 1957; Pervin, 1990). The primary reason for this is the field's substantive interest in personality variables, which by definition arrive at the researcher's lab with a history, precluding random assignment. The validity of state-trait isomorphism may allow some end to this problem. To the extent that states have the same properties as traits, experimenters should be able, as we did in Study 3, to randomly assign individuals to states and instruct 
them to behave in those ways. Thus, it is important to test betweenpersons relationships to see whether they hold within person and then to attempt experimental manipulation of the states. Future research must determine the reach of this potential.

\section{Implications for Explaining the Relationship Between Extraversion and Positive Affect}

The powerful and robust relationship between extraversion and positive affect has provoked considerable investigation into its explanation: What is it that extraverts do that makes them happier? The current findings do not indicate what explains this relationship; however, an additional contribution of the current findings is that they limit the class of potential explanations. Specifically, whatever explains the within-person relationship between extraversion and positive affect must vary rapidly within a person. All between-persons factors are ruled out as explanations of the within-person relationship, as such factors do not vary within a person and thus cannot explain variation within a person.

It seems likely that whatever explains the within-person relationship between extraversion and positive affect also explains the between-persons relationship between extraversion and positive affect. That is, the reason that extraverted people are happier than introverted people is likely to be the same as the reason that extraverted moments are happier than introverted moments. Thus, it seems likely that the explanation for the between-persons relationship must also be something capable of varying rapidly within person. One implication of this is that many third-variable explanations, such as social desirability or response style, are of much less concern. Another implication is that fixed or structural explanations, such as set points or the BAS, are less likely to explain the relationship. By looking at variation within an individual rather than treating individuals as wholes, we are steered away from such fixed explanations and toward more variable ones.

Although this study shows no variation in average levels of positive affect being explained by trait extraversion, another study designed specifically to detect between-persons relationships may find some between-persons variation in positive affect explained by trait extraversion but not by state extraversion. This portion may remain explainable by fixed or structural features of trait extraversion, although the more parsimonious conclusion is that the reason more extraverted individuals are happier is the same as the reason more extraverted moments are happier.

This is not to deny that structures or set points are involved in the extraversion-positive affect relationship, but it is to imply that their involvement must be reconceptualized. First, obviously some neurological or interpretative structure plays a role in the relationship, but the implication of the present findings is that differences between extraverts and introverts in such structures are not likely to explain differences between them in their happiness levels unless they first impact the likelihood of acting extraverted at any given moment (because differences in structures cannot explain differences in happiness in the same individual across hours). Second, although homeostatic set points are not consistent with the current data, allostatic processes may be possible to reconcile with the findings. Third, the findings also may be consistent with modified sensitivity-based explanations. Specifically, it is possible that individuals vary over the course of hours in how sensitive they are to positive feedback, and those hours in which they have greater sensitivity may be the hours in which they act more extraverted and are happier. Research showing considerable within-person variability in coping strategies suggests that individuals do vary rapidly in their reactions to stimuli (Stone et al., 1998). This finding is also consistent with biological explanations, assuming that the biological factors responsible for enhanced reward sensitivity (e.g., the BAS) also vary rapidly within person (Gable et al., 2000; Hoebel, Rada, Mark, \& Pothos, 1999). The important point is that any explanatory variable must not be a constant within the individual.

There are a large number of possible explanations of the withinperson relationship, and future research would fruitfully explore these possibilities. For example, positive feedback from others, attention from others, having an impact on others, being active rather than passive, coping strategies, or high levels of energy may all explain how individuals get from acting assertive, adventurous, and talkative to being happy. Some of these can be seen as especially likely mediators in the experiment in Study 3. However, all of these explanations are closely tied to the content of the extraversion trait rather than to some hidden byproduct-it is extraversion that is responsible, after all. In fact, it is unclear why rapid and frequent variation in extraverted behavior has so far received so little attention in most explanations of the relationship.

\section{Limitations}

There are at least three limitations to the current studies: causality, the U.S. college student sample, and reliance on self-reports. First, causality of the extraversion-positive affect relationship was not established in any of the studies. However, the point of the studies was to investigate whether the extraversion-positive affect relationship found in so many other studies also is evident within person. This is because a personality psychology that describes individuals ought to investigate whether important processes describe individuals at least as often as this psychology describes differences between individuals (Lamiell, 1997). Just as previous between-persons studies have not established whether extraversion causes positive affect, whether positive affect causes extraversion, or whether a third variable causes both, the current studies do not address that issue of causality. Study 3 comes closest to establishing causality, but there is a possible confound in that study. Specifically, to warm up participants, we instructed them to describe a recent time in which they acted extraverted or introverted. It is possible that this memory induced the positive affect difference between the two conditions, although a difference of two and a half standard deviations is unlikely to be due to memory.

A second potential limitation of this research is the use of U.S. college students. Although this is a common problem in psychological research, it becomes a problem of particular concern in the current study when the findings reveal that every single individual in Study 1 showed a positive relationship between acting extraverted and experiencing positive affect. A reasonable reaction to these results is to suggest that they may not replicate in adults or in more diverse samples. However, given the diversity of samples and countries in which the between-persons relationship has been found (Lucas et al., 2000), it is unlikely that a large number of individuals would fail to show a positive relationship; whether the finding holds in other countries, such as Japan, is worth testing. Furthermore, what mediator turns out to explain the relationship between extraverted states and positive affect is highly relevant to questions of how far the findings generalize. For example, if the 
explanation is energy level, the finding may be more likely to generalize to more collective cultures. In any event, such a reaction shows how strong the intuition is that the extraversion-positive affect relationship is relevant to only a few individuals.

Finally, there was a heavy reliance on self-reports of behavior and of affect in the present studies. Again, this was intentional in the attempt to remain as close as possible to the methodology used in between-persons studies of the relationship, which nearly uniformly rely on self-reports. However, self-report methodology calls into question the validity of the reports, that self-reports of behavior did not reflect actual behavior. There are at least three reasons we expect that the findings are not an artifact of our use of self-report measures. First, Fleeson (2001) presented evidence that such state reports are valid as indicators of the individual's actual behavior, showing that traits were predicted significantly and differentially from current situations. The current article adds further validity evidence by showing that extraversion states are correlated with positive affect states. Second, the analyses were conducted within person, meaning that individuals were compared with themselves at different times. Any biases in self-report would have had to vary within the person and also covary with extraversion and positive affect. Third, Study 3 was able to use observer reports, and participants who were instructed to act extraverted were in fact rated by observers as acting more extraverted. Although some evidence has suggested that individuals indeed report their own extraverted behavior rather accurately (Borkenau \& Ostendorf, 1987; Gosling, John, Craik, \& Robins, 1998), more research is needed on the accuracy of self-reports of behavior, especially if similar types of within-person, process-oriented personality research is to proceed.

One additional limitation worth mentioning is the small number of reports per individual in Study 2. This produced less reliable estimates of the within-person relationship across weeks, although the nearly unanimous consistency of findings across participants (51 of 57 showed a positive relationship) ameliorates this limitation to some extent. Replication with more weeks per individual would solidify this finding.

\section{Conclusion}

A long-standing dilemma in personality psychology is whether to pursue idiographic knowledge-knowledge about the ongoing psychological functioning of an individual - or nomothetic knowledge- knowledge of general principles that apply to many individuals. The solution is the kind of idiothetic research reported herein (Epstein, 1983; Jones \& Nesselroade, 1990; Lamiell, 1981; Larsen, 1989; Valsiner, 1986). First, collect lots of data on one individual over multiple occasions and determine whether a general principle characterizes this individual's psychological functioning. Second, replicate this procedure across many individuals to determine how generally this principle applies. In the present studies, we were able to provide a new understanding and credibility to the extraversion-positive affect relationship with this approach by showing that it does characterize the ongoing psychological functioning of individuals, despite intuitions to the contrary, and that it is generally characteristic of possibly all individuals.

\section{References}

Allport, G. W. (1937). Personality: A psychological interpretation. New York: Holt.

Borkenau, P., \& Ostendorf, F. (1987). Retrospective estimates of act frequencies: How accurately do they reflect reality? Journal of Personality and Social Psychology, 52, 626-638.

Borkenau, P., \& Ostendorf, F. (1998). The Big Five as states: How useful is the five-factor model to describe intra-individual variations over time? Journal of Research in Personality, 32, 202-221.

Brown, K. W., \& Moskowitz, D. S. (1998). Dynamic stability of behavior: The rhythms of our interpersonal lives. Journal of Personality, 66, $105-134$.

Buss, D. M., \& Craik, K. H. (1983). The act frequency approach to personality. Psychological Review, 90, 105-126.

Cantor, N. (1990). From thought to behavior: "Having" and "doing" in the study of personality and cognition. American Psychologist, 45, 735-750.

Cantor, N., Norem, J., Langston, C., Zirkel, S., Fleeson, W., \& CookFlannagan, C. (1991). Life tasks and daily life experience. Journal of Personality, 59, 425-451.

Carver, C. S., \& Scheier, M. F. (1999). Themes and issues in the selfregulation of behavior. In R. S. Wyer, Jr. (Ed.), Perspectives on behavioral self-regulation: Advances in social cognition (Vol. 12, pp. 1-105). Hillsdale, NJ: Erlbaum.

Carver, C. S., Sutton, S. K., \& Scheier, M. F. (2000). Action, emotion, and personality: Emerging conceptual integration. Personality and Social Psychology Bulletin, 26, 741-751.

Cattell, R. B., Cattell, A. K. S., \& Rhymer, R. M. (1947). P-technique demonstrated in determining psycho-physiological source traits in a normal individual. Psychometrika, 12, 267-288.

Côté, S., \& Moskowitz, D. S. (1998). On the dynamic covariation between interpersonal behavior and affect: Prediction from neuroticism, extraversion, and agreeableness. Journal of Personality and Social Psychology, 75, 1032-1046.

Cronbach, L. J. (1957). The two disciplines of scientific psychology. American Psychologist, 12, 671-684.

Davidson, R. J. (1998). Affective style and affective disorders: Perspectives from affective neuroscience. Cognition and Emotion, 12, 307-330.

De Raad, B., Hendriks, A. A. J., \& Hofstee, W. K. B. (1994). The Big Five: A tip of the iceberg of individual differences. In C. F. Halverson, Jr., G. A. Kohnstamm, \& R. P. Martin (Eds.), The developing structure of temperament and personality from infancy to adulthood (pp. 91-109). Hillsdale, NJ: Erlbaum.

Depue, R. A., \& Collins, P. F. (1999). Neurobiology of the structure of personality: Dopamine, facilitation of incentive motivation, and extraversion. Behavioral and Brain Sciences, 22, 491-569.

Diener, E., \& Lucas, R. E. (1999). Personality and subjective well-being. In D. Kahneman, E. Diener, \& N. Schwarz (Eds.), Well-being: The foundations of hedonic psychology (pp. 213-229). New York: Russell Sage Foundation.

Emmons, R. A., \& Diener, E. (1986). Influence of impulsivity and sociability on subjective well-being. Journal of Personality and Social Psychology, 50, 1211-1215.

Emmons, R. A., Diener, E., \& Larsen, R. J. (1986). Choice and avoidance of everyday situations and affect congruence: Two models of reciprocal interactionism. Journal of Personality and Social Psychology, 51, 815826.

Epstein, S. (1979). The stability of behavior? I. On predicting most of the people much of the time. Journal of Personality and Social Psychology, 37, 1097-1126.

Epstein, S. (1983). A research paradigm for the study of personality and emotions. In R. Dienstbier (Series Ed.) \& M. M. Page (Vol. Ed.), Nebraska symposium on motivation: Vol. 30: Personality-Current theory and research (pp. 91-154). Lincoln: University of Nebraska Press.

Eysenck, H. J. (1981). General features of the model. In H. J. Eysenck (Ed.), A model for personality (pp. 1-37). New York: Springer-Verlag. 
Fiske, D. W. (1961). The inherent variability of behavior. In D. W. Fiske \& S. R. Maddi (Eds.), Functions of varied experience (pp. 326-354). Homewood, IL: Dorsey Press.

Fleeson, W. (2001). Toward a structure- and process-integrated view of personality: Traits as density distributions of states. Journal of Personality and Social Psychology, 80, 1011-1027.

Fleeson, W., \& Cantor, N. (1995). Goal relevance and the affective experience of daily life: Ruling out situational explanations. Motivation and Emotion, 19, 25-57.

Fridhandler, B. M. (1986). Conceptual note on state, trait, and the statetrait distinction. Journal of Personality and Social Psychology, 50, 169-174.

Funder, D. C. (2001). Personality. Annual Review of Psychology, 52, 197-221.

Gable, S. L., \& Reis, H. T. (1999). Now and then, them and us, this and that: Studying relationships across time, partner, context, and person. Personal Relationships, 6, 415-432.

Gable, S. L., Reis, H. T., \& Elliot, A. J. (2000). Behavioral activation and inhibition in everyday life. Journal of Personality and Social Psychology, 78, 1135-1149.

Goldberg, L. R. (1992). The development of markers for the Big-Five factor structure. Psychological Assessment, 4, 26-42.

Gosling, S. D., John, O. P., Craik, K. H., \& Robins, R. W. (1998). Do people know how they behave? Self-reported act frequencies compared with on-line codings by observers. Journal of Personality and Social Psychology, 74, 1337-1349.

Gray, J. A. (1971). The psychophysiological basis of introversionextraversion. Behavior Research and Therapy, 8, 249-266.

Gross, J. J., Sutton, S. K., \& Ketelaar, T. (1998). Relations between affect and personality: Support for the affect-level and affective-reactivity views. Personality and Social Psychology Bulletin, 24, 279-288.

Haunschild, P. R., Moreland, R. L., \& Murrell, A. J. (1994). Sources of resistance to mergers between groups. Journal of Applied Social Psychology, 24, 1150-1178.

Headey, B., \& Wearing, A. (1989). Personality, life events, and subjective well-being: Toward a dynamic equilibrium model. Journal of Personality and Social Psychology, 57, 731-739.

Hoebel, B. G., Rada, P. V., Mark, G. P., \& Pothos, E. N. (1999). Neural systems for reinforcement and inhibition of behavior: Relevance to eating, addiction, and depression. In D. Kahneman, E. Diener, \& N. Schwarz (Eds.), Well-being: The foundations of hedonic psychology (pp. 558-572). New York: Russell Sage Foundation.

Jones, C. J., \& Nesselroade, J. R. (1990). Multivariate, replicated, singlesubject, repeated measures designs and p-technique factor analysis: A review of intraindividual change studies. Experimental Aging Research, 16, 171-183.

Lamiell, J. T. (1981). Toward an idiothetic psychology of personality. American Psychologist, 36, 276-289.

Lamiell, J. T. (1997). Individuals and the differences between them. In R. Hogan, J. A. Johnson, \& S. R. Briggs (Eds.), Handbook of personality psychology (pp. 117-141). San Diego, CA: Academic Press.

Larsen, R. J. (1989). A process approach to personality psychology: Utilizing time as a facet of data. In D. M. Buss \& N. Cantor (Eds.), Personality psychology: Recent trends and emerging directions (pp. 177-193). New York: Springer-Verlag.

Larsen, R. J., \& Ketelaar, T. (1991). Personality and susceptibility to positive and negative emotional states. Journal of Personality and Social Psychology, 61, 132-140.

Lucas, R. E., Diener, E., Grob, A., Suh, E. M., \& Shao, L. (2000). Cross-cultural evidence for the fundamental features of extraversion. Journal of Personality and Social Psychology, 79, 452-468.

Lucas, R. E., \& Fujita, F. (2000). Factors influencing the relation between extraversion and pleasant affect. Journal of Personality and Social Psychology, 79, 1039-1056.
Lykken, D., \& Tellegen, A. (1996). Happiness is a stochastic phenomenon. Psychological Science, 7, 186-189.

McCrae, R. R., \& Costa, P. T. Jr. (1987). Validation of a five-factor model of personality across instruments and observers. Journal of Personality and Social Psychology, 52, 81-90.

McCrae, R. R., \& Costa, P. T. Jr. (1990). Personality in adulthood. New York: Guilford Press.

McGregor, I, \& Little, B. R. (1998). Personal projects, happiness, and meaning: On doing well and being yourself. Journal of Personality and Social Psychology, 74, 494-512.

Mischel, W. (1968). Personality and assessment. New York: Wiley.

Moskowitz, D. S. (1982). Coherence and cross-situational generality in personality: A new analysis of old problems. Journal of Personality and Social Psychology, 43, 754-768.

Moskowitz, D. S., \& Côté, S. (1995). Do interpersonal traits predict affect? A comparison of three models. Journal of Personality and Social Psychology, 69, 915-924.

Murray, H. A. (1938). Explorations in personality: A clinical and experimental study of fifty men of college age. New York: Oxford University Press.

Nesselroade, J. R. (1988). Some implications of the trait-state distinction for the study of development over the life span: The case of personality. In P. B. Baltes, D. L. Featherman, \& R. M. Lerner (Eds.), Life-span development and behavior (Vol. 8, pp. 163-189). Hillsdale, NJ: Erlbaum.

Nesselroade, J. R. (1991). Interindividual differences in intraindividual change. In L. M. Collins \& J. L. Horn (Eds.), Best methods for the analysis of change (pp. 92-105). Washington, DC: American Psychological Association.

Patrick, A. W., \& Zuckerman, M. (1977). An application of the state-trait concept to the need for achievement. Journal of Research in Personality, 11, 459-465.

Pavot, W., Diener, E., \& Fujita, F. (1990). Extraversion and happiness. Personality and Individual Differences, 11, 1299-1306.

Pervin, L. A. (1990). A brief history of modern personality theory. In L. A Pervin (Ed.), Handbook of personality: Theory and research (pp. 3-18). New York: Guilford Press.

Pervin, L. A. (1994). A critical analysis of current trait theory. Psychological Inquiry, 5, 122-130.

Roberts, B. W., \& Donahue, E. M. (1994). One personality, multiple selves: Integrating personality and social roles. Journal of Personality, 62, 199-218.

Rusting, C. L., \& Larsen, R. J. (1998). Personality and cognitive processing of affective information. Personality and Social Psychology Bulletin, 24, $200-213$.

Ryan, R. M, \& Deci, E. L. (2001). On happiness and human potentials: A review of research on hedonic and eudaimonic well-being. Annual Review of Psychology, 52, 141-166.

Seligman, M., \& Csikszentmihalyi, M. (2000). Positive psychology: An introduction. American Psychologist, 55, 5-14.

Sheldon, K. M., \& King, L. (2001). Why positive psychology is necessary. American Psychologist, 56, 216-217.

Sheldon, K. M., Ryan, R. M., Rawsthorne, L. J., \& Ilardi, B. (1997). Trait self and true self: Cross-role variation in the Big-Five personality traits and its relations with psychological authenticity and subjective wellbeing. Journal of Personality and Social Psychology, 73, 1380-1393.

Singer, J. D. (1998). Using SAS PROC MIXED to fit multilevel models, hierarchical models, and individual growth models. Journal of Educational and Behavioral Statistics, 24, 323-355.

Spielberger, C. D., Lushene, R. E., \& McAdoo, W. G. (1977). Theory and measurement of anxiety states. In R. B. Cattell \& R. M. Dreger (Eds.), Handbook of modern personality theory (pp. 239-253). Washington, DC: Hemisphere

Stone, A. A., Schwartz, J. E., Neale, J. M., Shiffman, S., Marco, C. A., Hickcox, M., et al. (1998). How accurate are current coping assess- 
ments? A comparison of momentary versus end-of-day reports of coping efforts. Journal of Personality and Social Psychology, 74, 1670-1680.

Stone, A. A., Shiffman, S. S., \& DeVries, M. W. (1999). Ecological momentary assessment. In D. Kahneman, E. Diener, \& N. Schwarz (Eds.), Well-being: The foundations of hedonic psychology (pp. 26-39). New York: Russell Sage Foundation.

Tennen, H., Affleck, G., Armeli, S., \& Carney, M. A. (2000). A daily process approach to coping: Linking theory, research, and practice. American Psychologist, 55, 626-636.

Tennen, H., Suls, J., \& Affleck, G. (1991). Personality and daily experience: The promise and the challenge. Journal of Personality, 59, 313337.
Valsiner, J. (1986). Between groups and individuals: Psychologists' and laypersons' interpretations of correlational findings. In J. Valsiner (Ed.), The individual subject and scientific psychology (pp. 113-151). New York: Plenum.

Watson, D., Clark, L. A., \& Tellegen, A. (1988). Development and validation of brief measures of positive and negative affect: The PANAS scales. Journal of Personality and Social Psychology, 54, 1063-1070.

Received October 16, 2001

Revision received April 22, 2002

Accepted May 2, 2002

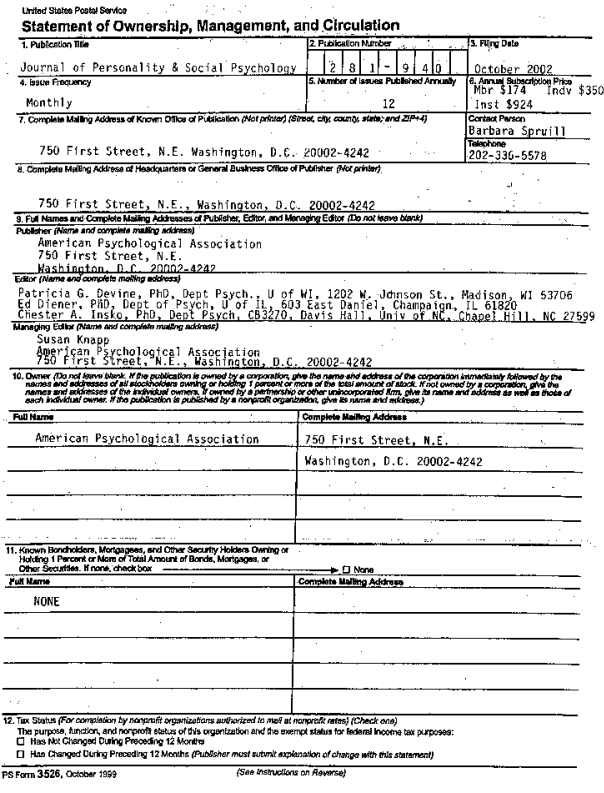

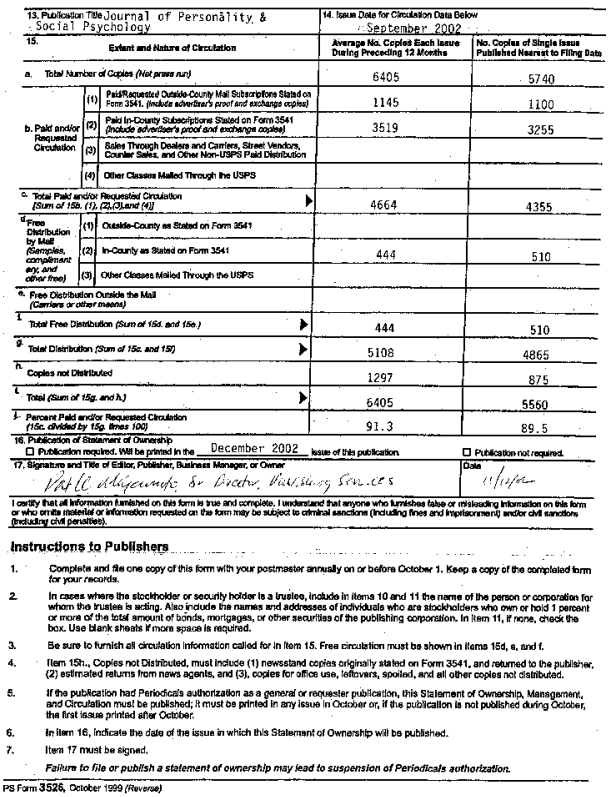

